\title{
Recommendations regarding emergency head and neck procedures during coronavirus disease-2019
}

\author{
Procedimientos de emergencia en Cabeza y Cuello. Recomendaciones sobre la pandemia \\ por COVID-19
}

\author{
Alejandro Yanzon, Natalia Gomez, Luis Boccalatte*, Juan José Larrañaga, and Marcelo Figari \\ Head and Neck Section, General Surgery Service, Hospital Italiano de Buenos Aires, Buenos Aires, Argentina
}

\begin{abstract}
The coronavirus disease-2019 (COVID-19) has spread globally and is considered a world health emergency. Healthcare professionals represent an important percentage of the infected population, with otolaryngologists and head and neck surgeons at particular risk. Elective procedures have been strongly discouraged, but urgent disorders still entail a hazardous setting. We performed a non-systematic review of the publications and guidelines regarding Head and Neck surgical emergencies management in the context of the COVID-19 pandemic. The literature describing management of the disease was also reviewed to adapt conventional treatment to the present circumstances. A concise and specific compilation of practical recommendations was made with the aim of improving management of emergencies involving the head and neck region, while offering a safe alternative for patients and healthcare providers. In addition, we have made a brief summary of how these recommendations were adapted based on our socio-economic background and available health resources.
\end{abstract}

Key words: Head and neck. Revision. SARS-Cov-2. Emergencies. Surgery.

\section{Resumen}

La enfermedad del coronavirus-2019 (COVID-19) se ha extendido a nivel mundial y se considera una emergencia sanitaria mundial. Los profesionales sanitarios representan un porcentaje importante de la población infectada, y los otorrinolaringólogos y cirujanos de cabeza y cuello corren un riesgo especial. Se han desaconsejado enérgicamente los procedimientos electivos, pero los trastornos urgentes aún implican un entorno peligroso. Realizamos una revisión no sistemática de las publicaciones y guías sobre el manejo de emergencias quirúrgicas de cabeza y cuello en el contexto de la pandemia de COVID-19. También se revisó la literatura que describe el manejo de la enfermedad con el fin de adaptar el tratamiento convencional a las circunstancias actuales. Se realizó una recopilación concisa y específica de recomendaciones prácticas con el objetivo de mejorar el manejo de las emergencias que involucran la región de la cabeza y el cuello, al tiempo que ofrece una alternativa segura para los pacientes y los proveedores de atención médica. Además, hemos hecho un breve resumen de cómo se adaptaron estas recomendaciones en función de nuestros antecedentes socioeconómicos y los recursos de salud disponibles.

Palabras clave: Cabeza y cuello. Revisión. SARS-Cov-2. Emergencias. Cirugía.

\footnotetext{
Correspondence:

*Luis Boccalatte

Juan D. Perón, 4190

Date of reception: 25-03-2021

$\mathrm{C} 1181 \mathrm{ACH}$, Buenos Aires, Argentina

Date of acceptance: 03-08-2021

E-mail: luis.boccalatte@hospitalitaliano.org.ar

DOI: $10.24875 / C I R U .21000275$

Cir Cir. 2021;89(6):827-835

Contents available at PubMed

www.cirugiaycirujanos.com

0009-7411/@ 2021 Academia Mexicana de Cirugía. Published by Permanyer. This is an open access article under the terms of the CC BY-NC-ND license (http://creativecommons.org/licenses/by-nc-nd/4.0/).
} 


\section{Introduction}

The new infectious disease caused by SARS CoV-2 coronavirus dieses-2019 (COVID-19) has spread rapidly and poses a challenge to the different healthcare systems worldwide. Daily reports from the World Health Organization (WHO) show an exponential growth in the numbers of infected persons and a large number of fatalities ${ }^{1}$.

Healthcare personnel is exposed to contagion'. Among care providers with the highest risk of infection are otolaryngologists (ENT), head and neck surgeons, and maxillofacial specialists ${ }^{2-6}$. Many scientific societies have issued guidelines and recommendations to decrease the risk of contagion ${ }^{7-11}$. Furthermore, an increasing number of publications warn about the risk of certain surgical procedures and advice regarding alternative options to minimize the possibility of infection for the healthcare team $2,5,12-17$.

In the head and neck area, there has been strong advice to avoid all elective procedures ${ }^{7-11,18}$. However, the chance of contagion remains, since urgent disorders still present a potentially dangerous scenario. The main goal of the present paper is to issue a document with practical recommendations for the management of emergencies in the head and neck region, in the context of the COVID-19 pandemic.

\section{Methods}

We performed a non-systematic literature search of publications and guidelines by the main scientific societies regarding the management of surgical emergencies of the head and neck, maxillofacial surgery and otolaryngology in the context of the SARS-CoV-2 pandemic. We also reviewed the published literature concerning the usual management of the mentioned disorders, to adapt treatments to the current context, and to offer a safe alternative for patients and the healthcare personnel. Finally, a brief summary of how these recommendations were adapted to our socioeconomic background and available health resources, was made.

\section{General recommendations for the management of emergencies}

1. Do not take urgent action if the necessary protective elements are not available. Protection of the healthcare personnel should be a priority. When this recommendation is not followed, both physicians and patients are endangered 19,20

2. However, it is mandatory to remark that the best protection for health personnel is to avoid contact of fluids with the airway. Never touch the face, nose and eyes with your hands. Hand washing is crucial

3. Communication between team members should be frequent and seamless. Careful selection of patients who will undergo surgery should be made with a multidisciplinary approach ${ }^{12,21}$

4. Whenever possible, a test to detect COVID-19 should be performed preoperatively on all patients. Knowledge regarding the patient's status will allow to adequately protect healthcare personnel and implement appropriate epidemiologic measures, and also to decrease healthcare costs related to the use of personal protective equipment (PPE) ${ }^{22}$

5. All patients with urgent conditions that have not been tested should be considered as COVID-19 positive $^{8}$. Viral load in the mucosa of the upper aerodigestive tract is high; therefore, its surgical exam entails an elevated risk of transmission. In the absence of a preoperative SARS CoV-2 test, precautions should be adopted as if the patient were positive ${ }^{13,23}$. The AOCMF (Craniomaxillofacial) Group of the AO Foundation suggests obtaining at least two negative COVID-19 tests, separated by a minimum period of $24 \mathrm{~h}$, given the possibility of false negative results ${ }^{8}$. Nevertheless, this policy is not applicable in most emergencies

6. If a tomographic exam is required for assessment, an additional chest computed tomography (CT) is advisable, to evaluate signs consistent with a respiratory infection ${ }^{15,24}$

7. PPE should be maximized, due to the high risk of aerosolization entailed in head and neck procedures. Consensus regarding PPE in procedures with a risk of aerosolization has been reached between most Otolaryngology, Head and Neck, and Maxillofacial Societies. Full PPE should consist of: face mask, goggles, N95 mask, FPP2, FPP3 or PAPRs (Powered AirPurifying Respirators) (or surgical masks with an integrated visor), gloves (preferably double gloves), and blood-repelling gown, plus head cover and shoe covers whenever possible $^{7,8,9,18,25}$. It is relevant to remember that the 
withdrawal of the PPE results a key point and has been described the risk of contamination and contagion notably increases during this step

8. One thing which is important to clarify is that the use of masks with valves only protects the person who uses them (entry of the virus). Those colleagues who are close to them are not protected because the particles of the virus are released while the person is exhaling

9. The operating room (OR) should be prepared for patients who have tested positive for COVID-19 and should have a negative pressure system ${ }^{26}$. Importantly, the OR should not receive positive pressure during the procedure to avoid spreading the SARS-CoV-2. After operating a suspicious or positive patient, a waiting period of at least $2 \mathrm{~h}$ is required before positive pressure can be restarted in the $\mathrm{OR}^{26}$

10. Surgical techniques should be adapted to reduce exposure risks; insufflation with carbon dioxide (CO2) should be avoided, as well as power-driven devices such as drills or electrocautery, which can generate aerosols. Surgical procedures should involve the fewest possible members of the team, and a senior surgeon should be the most experienced member. During patient intubation and extubation, the most experienced anesthesiologist and his/her assistant should be present in the $\mathrm{OR}^{21}$

11. All personnel should be trained in gowning and ungowning techniques and use of PPE to avoid auto-infection resulting from inadequate PPE removal $^{21,27}$. At our institution, we have implemented instructional videos, simulation programs and hands-on workshops to train all team members in these maneuvers, and train promoters who can convey their learning to others

12. When available, telemedicine is a useful resource for the care, follow-up and support of a selected group of patients ${ }^{28}$

13. Restructuring of medical residency programs and training programs is suggested, according to the human resources available. The main goals are optimizing the well-being of the medical team, complying with social distance recommendations and ensuring adequate patient care $^{29}$. We also advise to discontinue pre-graduate educational activities and scheduled rotations involving patient care.

\section{Recommendations for specific management during emergency situations}

\section{RESPIRATORY FAILURE}

A patient presenting with respiratory failure represents a medical emergency and is always a demanding situation for the medical team ${ }^{30,31}$.

The recommendations are:

1- The necessary equipment to manage a difficult airway should be available, as well as a trained medical personnel team ${ }^{32}$

2- The senior physician should be promptly involved, to avoid delays in decision making ${ }^{32}$

3- For cases requiring the participation of several team members, the discussion regarding management should be held at a prudent distance from the patient, to decrease the risk of contagion, whenever possible ${ }^{32}$

4- High flow cannulas and other non-invasive ventilation devices should be avoided, since they promote aerosolization. If oxygen is required, low-flow oxygen may be administered through a nasal cannula and it is recommended that the patient wear a face mask ${ }^{17}$

5- Any type of intubation is preferable to an emergency tracheostomy ${ }^{13}$

6- When intubation is required, recommendations are the following: $:^{14,17,33}$

a. The most experienced team member should perform the intubation

b. Videolaryngoscopy should be used to maximize procedure success

c. Rapid sequence intubation should be performed.

d.Prior to instrumenting the airway, intravenous lidocaine should be administered to decrease the cough reflex

e. Once the endotracheal tube (ETT) is in place, ventilation should begin only after the balloon or cuff has been inflated.

\section{Cannot intubate, cannot oxygenate situations}

An emergency front of neck airway (eFONA) should be performed. When the cricothyroid membrane is palpable cricothyroidotomy is recommended, and if that were not the case, tracheostomy is indicated. A Frova intubation introducer and a scalpel should be preferably used, with a scalpel-bougie technique. 


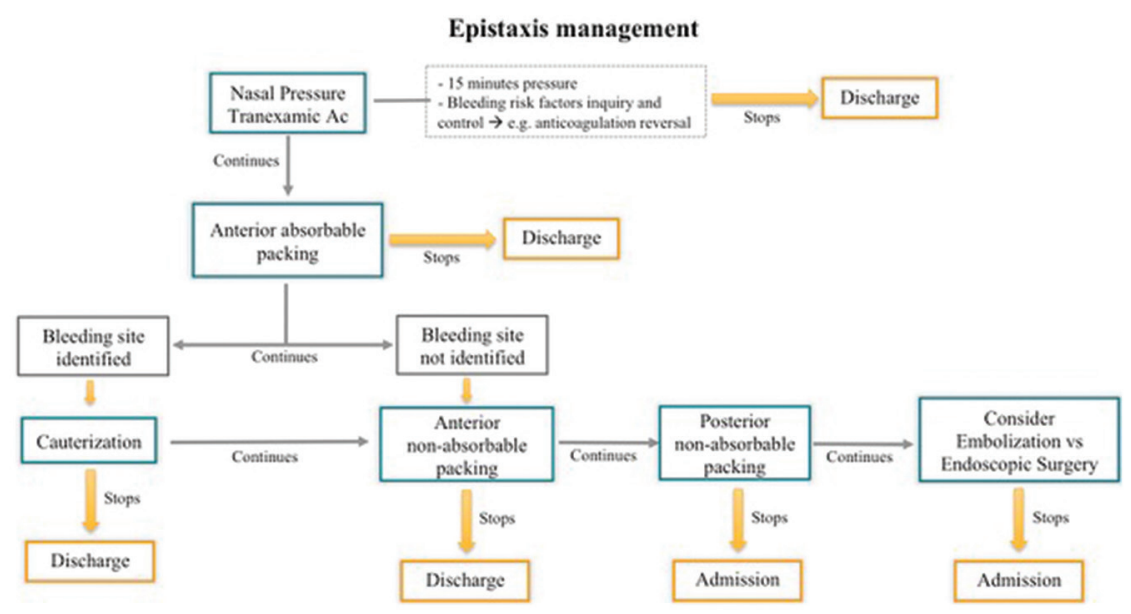

Figure 1. Summary of epistaxis management. Notice that surgical management should be considered as the last resort.

Contrary to usual practice, further attempts to deliver oxygen from above should not occur during the performance of eFONA, to avoid aerosolization of viruscontaining fluids when the trachea is punctured ${ }^{10,30,31}$.

\section{TRACHEOSTOMY IN A VENTILATED PATIENT}

The procedure should be performed by the bettertrained and experienced personnel $\left.\right|^{14,34}$.

1. Expose the area where the tracheal window will be opened

2. Do not remove the ETT, but rather introduce it up to the limit with the carina

3. With the end of the ETT located distal to the site of incision, ensure the cuff is properly inflated

4. Following pre-oxygenation, confirm that the patient is in apnea and without respiratory movements

5. Perform tracheal window

6. Deflate the ETT cuff and withdraw it until it is located proximal to the site of the window

7. Place the tracheostomy cannula, which should be non-fenestrated and with a cuff

8. Inflate the cuff and connect it to the ventilation system

9. Restart ventilation

10. Secure the ETT with sutures and fastening straps.

Of note, some authors have recognized percutaneous tracheostomy as a procedure with higher risk of aerosolization compared to conventional tracheostomy ${ }^{14}$. However, at present this subject remains controversial.
If a patient were to undergo tracheostomy due to prolonged intubation, the procedure should be delayed as much as possible. Most patients, who can undergo extubation, will do so after 5-10 days. In addition, the viral load decreases progressively ${ }^{34}$. Hence, the recommendation is to perform tracheostomy after day 21 post intubation ${ }^{35}$.

\section{Epistaxis}

The goal of the following recommendations is to avoid procedures that increase the risks for healthcare personnel, and to manage patients with epistaxis safely, preferably with ambulatory care ${ }^{6,36}$.

The recommendations are (Fig. 1):

1. Begin nasal compression and continue for 15 min, while patient is enquired about risk factors and such factors are addressed. In the absence of contraindications, administer tranexamic acid $^{36-38}$

2. If bleeding persists, nasal packing with absorbable material is recommended, to decrease the risk of contagion during packing removal. Examples of such materials are: Spongostan ${ }^{\circledR}$, Nasopore $^{\circledR}$, Surgiflo ${ }^{\circledR}$, etc. ${ }^{38}$

3. In case of persistent bleeding, and if the bleeding vessel can be identified during rhinoscopy, cauterization with silver nitrate is advised ${ }^{36,38}$

4. When bleeding cannot be controlled, anterior nasal packing with non-absorbable material is recommended. An inflatable device, such as Rapid Rhino ${ }^{\circledR}$ is preferred, to save time and avoid extensive manipulation of the nasal mucosa ${ }^{38,39}$ 
5. 5- If bleeding still persists or if posterior epistaxis is suspected, a posterior packing should be performed, preferably using inflatable, double balloon devices (e.g., Rapid Rhino ${ }^{\oplus}$ ) to save time and avoid extensive manipulation of the nasal mucosa $^{36,38,39}$

6. Endoscopic surgery and nasal embolization are used as last resources ${ }^{40,41}$

7. All patients whose bleeding has been controlled following steps $1,2,3$, and 4 can be managed as outpatients, with telephone follow-up and telemedicine resources. An ambulatory follow-up after 24-48 $\mathrm{h}$ is advised. The patients who require posterior packing, embolization or surgery should be admitted for appropriate monitoring ${ }^{36,38}$.

\section{Maxillofacial trauma}

Emergency surgery in the maxillofacial area should be limited to the surgical management of facial fractures that require open reduction and internal fixation (ORIF).

1- General recommendations for facial fractures treatment are: (a) perform incisions with a scalpel, (b) avoid the use of electrocautery, (c) prefer the use of low-power bipolar cautery, (d) when drilling is required, use a low speed and avoid flushing, (e) use self-drilling screws, (f) if osteotomies are required, use osteotomes instead of high-speed saws or drills, (g) the use of absorbable sutures is recommended, as well as a device for continuous suction of saliva ${ }^{2,15}$

2- Mandibular fractures:

a.Consider closed reduction with intermaxillary fixation (IMF), securing the occlusal relationships using self-drilling screws and elastics

b. For fractures requiring ORIF, consider intra-oral placement of the IMF screws and elastics for control of the occlusion, seal the oral cavity with a self-adhesive patch and perform reduction and fixation using extraoral approaches.

3- Midface fractures:

a. Consider a closed reduction only if the fracture remains stable after reduction

b. Use Carroll-Girard screws for reduction of the zygoma (avoiding an intra-oral incision) if two fixation points are enough to stabilize the fracture (frontozygomatic and infraorbital rim fixation)

c. Most zygomatic arch fractures do not require surgical treatment d. We suggest not operating orbital fractures in an emergency setting, except when there is content entrapment, hematoma with compromised vision, orbital apex syndrome, or an upper orbital fissure syndrome

e. It is best to postpone surgeries for nasal fractures, except for the drainage of septal hematomas.

4- Upper face/frontal sinus procedures:

a.Consider postponing non-functional fractures of the frontal sinus or frontal bone

b. Avoid endonasal endoscopic procedures

c. If cranialization or obliteration of the sinus becomes necessary, remove the mucosa manually.

5- Facial soft tissues ${ }^{16}$ :

(a) if there is damage to critical structures, such as the facial nerve, other cranial nerves, eyelids, lacrimal apparatus or the nose, the patient should be examined by a craniomaxillofacial surgeon for early resolution, (b) lesions to the lacrimal apparatus or eyelids require assessment of the status of the eye globe, (c) most oral lacerations do not require closure.

\section{Foreign body in the upper aerodigestive tract}

Accidental swallowing of foreign bodies is a medical emergency, since they may damage the mucosa and cause severe complications with high morbidity and mortality. ${ }^{42}$

Endoscopic exams offer a diagnostic and therapeutic tool, but entail a high risk of contagion ${ }^{9,18,42}$. The recommendations below address the appropriate selection of patients, to avoid unnecessary exposure in cases in which the suspicion of foreign body is low.

1. Obtain a careful history, to assess the actual risk of the patient having swallowed a foreign body: the nature of the object, its composition (radiopaque or radiolucent) and estimate the potential damage to the aerodigestive tract mucosa (e.g., a chicken bone, fish bone, batteries) ${ }^{42}$

2. Look carefully for key signs and symptoms: drooling, stridor, dysphonia, crepitation, neck edema, emphysema, and difficulty breathing ${ }^{42,43}$

3. If the history is inconsistent and the patient has no symptoms, the recommendation is to obtain an X-ray of the neck's soft tissues (lateral view) or tomographic exam. In the absence of consistent radiologic or tomographic signs, (emphysema, 
neck edema, air in the cervical esophagus, or presence of a foreign body), the recommendation is not to perform nasolaryngoscopy, discharge the patient with clear instructions to watch for abnormal symptoms, and follow him/her with telemedicine resources and ambulatory control ${ }^{43}$

4. If the history is consistent with ingestion of a foreign body, the patient has symptoms, and/or radiological signs are suggestive, a nasolaryngoscopy is recommended ${ }^{43}$

5. When nasolaryngoscopy is necessary ${ }^{13,42-44}$ :

a.It should be performed by the most experienced personnel

b.Videoendoscopy is the preferable method, since it allows to maintain a greater distance from the patient

c. Local anesthetic and decongestive agents should be applied before the procedure, preferably through pledgets, to decrease sneezing and cough reflexes. ${ }^{45}$

\section{Deep neck infections (DNI)}

DNI comprise various disorders that can potentially lead to severe complications. Early diagnosis is essential, and usual management comprises strict airway control, antibiotic therapy, and surgical drainage. Open drainage entails a risky situation for healthcare providers and may result in a prolonged hospital admission.

The SARS-CoV-2 pandemic forces us to find reasonable alternatives, with less aggressive treatments but without compromising patient safety. Many DNI will probably be managed as usual, implementing the safety measures known to all healthcare personnel. However, a selected group of patients may be treated differently, without endangering their health and with less risk to the medical team.

The recommendations are (Fig. 2):

1. Patients with $\mathrm{DNI}$ and a compromised airway should be managed with antibiotics and open drainage $e^{46-48}$

2. In open drainages, it is advisable to avoid transmucosal approaches. If such approaches are necessary, a scalpel should be used ${ }^{23}$

3. For patients without a compromised airway, with a well-defined and unilocular abscess, an imageguided, percutaneous drainage is advised. Such approach requires a shorter admission time and has proven to be a safe and effective option in these patients ${ }^{47-50}$

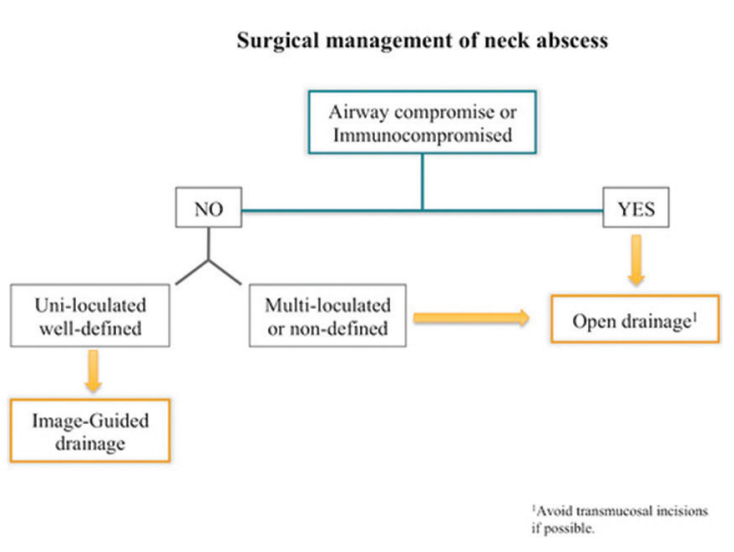

Figure 2. Summary of neck abscess surgical management. Notice that mucosal approach should be avoided if possible. Algorithm adapted from Biron et al. Surgical vs ultrasound-guided drainage of deep neck space abscesses: a randomized controlled trial: surgical vs ultrasound drainage. J Otolaryngol Head Neck Surg. 2013;42:18.

4. During percutaneous drainage, a catheter may be left in place until abscess resolution. A central line or $7 \mathrm{Fr}$. an equivalent catheter may be used ${ }^{46,47,50}$. Pigtail type drainages are not recommended for abscesses smaller than $1.5 \mathrm{~cm}$ in size ${ }^{50}$

5. In abscesses secondary to a dental infection, the definitive resolution of the original dental problem may be delayed, and managed on an ambulatory basis $^{47,48,51}$.

\section{Peritonsillar abscess (PTA)}

Unless adequately treated, a PTA may progress and compromise the airway, extend to the deep tissues of the neck and be life threatening ${ }^{52}$. The goal of the recommendations listed below is to decrease exposure during patient evaluation and treatment, as well as to reduce hospitalization rates.

1. Oral exams should be avoided whenever possible. If needed, we suggest that patients rinse their mouth and gargle several times with mouthwash containing topical povidone-iodine ${ }^{53}$

2. When imaging methods are required, tomography is suggested ${ }^{54}$. Transoral ultrasound should be avoided ${ }^{55}$

3. Many PTA may be treated safely only with medical treatment, without needle aspiration or incision and drainage. Medical treatment should include antibiotics, pain relievers, and a short course of low dose steroids (care must be taken if COVID-19 is suspected) ${ }^{55-58}$. They do require a 
strict clinical follow-up to detect patients who might require surgical treatment 52,53

4. Surgical drainage is recommended in cases of $52-54$ :

a.Compromised airway

b. Extension to the parapharyngeal or retropharyngeal spaces

c. Sepsis or bacteremia

d. Patients initially treated medically who do not improve clinically or whose clinical condition worsens.

5. If surgical drainage is required, we suggest performing needle aspiration rather than incision and drainage $^{59}$

6. Hospital admission is advised in patients with:

a.Compromised airway

b. Sepsis

c. Diabetes or other conditions with a compromised immune system

d.Oral intolerance: in this group, initial intravenous treatment in the emergency room is recommended. If no improvement occurs after 3-4 $\mathrm{h}$ of observation, hospital admission is advised $^{53,60}$. By contrast, if patients start tolerating oral intake and show clinical improvement, ambulatory management can be implemented.

7. Patients without the mentioned conditions and who tolerate oral intake (initially or following medical treatment) should be followed with ambulatory management, even if they have previously required surgical drainage ${ }^{53,56,60}$.

\section{Unique steps based on our medical system, culture, resource and priorities}

Argentina reported the first imported case on March 3, 2020. Early on, learning about the experience with the disease in Asia and Europe, our government closed the country's borders and imposed a lockdown with severe restrictions to circulation of people (March 20 ), which allowed better preparation of public and private healthcare resources.

Ninety days after implementing these measures, the healthcare system is burdened, but not overloaded (as of June 15, 32,000 cases have been reported and 850 people have died).

Although at the beginning, like in the rest of the world, only emergencies and oncologic cases that could not be delayed received medical care, today many of the healthcare institutions are beginning to accept elective surgery patients, at $30 \%$ of their capacity.
Our institution is a 750-bed private university hospital. It is considered one of the best medical institutions of Argentina; however, its financial resources are limited.

Like other healthcare centers of Argentina, we have had to adapt safety measures and recommendations to our local reality.

\section{PPE}

Initially, there were many problems with the supply of N95 masks. Following the guidelines accepted by the manufacturers themselves, we use them for 15 days (provided that they are used for less than $8 \mathrm{~h}$ a day), and they are sterilized with hydrogen peroxide, which prolongs their life span and to preserve equipment. To avoid soiling them with fluids, a regular surgical mask is placed on top of the N95.

Blood-repellent gowns in good condition are also re-sterilized.

\section{COVID test}

Initially, we did not have the possibility of performing large scale COVID PCR tests, therefore all patients were considered suspicious cases and maximum protection was implemented without exceptions. CurrentIy, the Institution has PCR tests with results available in $4 \mathrm{~h}$. When urgent cases allow time for performing the test, only one swab is obtained.

\section{Patients who have been vaccinated ${ }^{61}$}

Systemic respiratory vaccines generally provide limited protection against viral replication and shedding within the airway, as this requires a local mucosal secretory IgA response. Preclinical studies of adenovirus and mRNA candidate vaccines demonstrated persistent virus in nasal swabs despite preventing COVID-19. This suggests that systemically vaccinated patients, while asymptomatic, may still become infected and transmit live virus from the upper airway.

Until further knowledge is acquired regarding mucosal immunity following systemic vaccination, otolaryngology and head and neck surgeons should maintain precautions against viral transmission to protect the proportion of persistently vulnerable patients who exhibit subtotal vaccine efficacy or waning immunity or who defer vaccination. 


\section{ORs}

Our Hospital does not have ORs with negative pressure; hence, we have assigned specific ORs for patients with suspected or confirmed COVID, and in them the air conditioning equipment has been disabled to avoid positive pressure. Furthermore, the use of patient warming devices is avoided, since they increase ambient temperature and may result in the fogging of protective equipment.

\section{Telemedicine}

Although the Hospital has its own telemedicine system, many patients are not able to use it. The main limiting factors are lack of access to hardware, low connectivity, lack of education, advanced age, or other socio-economic reasons. These hurdles have been partially overcome with the use of instant messaging apps or telephone calls, and for cases in which effective communication has been achieved, the resulting information is recorded in the patient's electronic medical record.

\section{Adaptation to specific management of emergencies}

In ventilated patients who require a tracheostomy, our preferred procedure is a fiberoptic bronchoscopy-guided percutaneous dilatational tracheostomy, since in our experience it offers a safer and faster option. It is performed preferably 21 days after initiating mechanical ventilation, and requires only two operators, either an anesthesiologist or intensive care physician to perform the bronchoscopy, and the surgeon. Procedures are performed at the patient's bedside in the intensive care unit. To contain costs, we do not use disposable endoscopes ${ }^{62}$.

For the management of neck abscesses, given the cost of commercial drainage sets, we prefer the use of central line catheters.

Fortunately, for all other urgent procedures we have the appropriate materials available and follow the recommendations mentioned before.

\section{Conclusion}

The SARS CoV-2 (COVID-19) pandemic poses a threat to the general population as well as to healthcare workers. It is paramount to adapt our practices and take all necessary precautions to decrease the risk of contagion, while offering our patients safe and effective treatments. In this paper, we have reviewed several recommendations and suggestions, which we hope will contribute to optimize the management of head and neck emergencies in the context of this pandemic.

\section{Funding}

The authors declare that no funds or financial support were received for the development of this article.

\section{Conflicts of interest}

The authors disclose no conflicts of interest.

\section{Ethical disclosures}

Protection of human and animal subjects. The authors declare that no experiments were performed on humans or animals for this study.

Confidentiality of data. The authors declare that they have followed the protocols of their work center on the publication of patient data.

Right to privacy and informed consent. The authors declare that no patient data appear in this article.

\section{References}

1. World Health Organization. Coronavirus Disease 2019 (COVID-19) Situation Report-82. Geneva: World Health Organization; 2019. Available from: https://www.who.int/docs/default-source/coronaviruse/situation-reports/20200411-sitrep-82-covid-19.pdf?sfvrsn=74a5d15_2 [Last accessed on 2020 Apr 12].

2. Meng L, Hua F, Bian Z. Coronavirus disease 2019 (COVID-19): emerging and future challenges for dental and oral medicine. J Dent Res. 2020;99: 481-7.

3. Koh D. Occupational risks for COVID-19 infection. Occup Med (Lond). 2020;70:3-5.

4. Lai TH, Tang EW, Chau SK, Fung KS, Li KK. Stepping up infection control measures in ophthalmology during the novel Coronavirus outbreak: an experience from Hong Kong. Graefes Arch Clin Exp Ophthalmol. 2020;258:1049-55.

5. Chan JY, Wong EW, Lam W. Practical aspects of otolaryngologic clinical services during the 2019 novel Coronavirus epidemic: an experience in Hong Kong. JAMA Otolaryngol Head Neck Surg. 2020;146:519-20.

6. Kowalski LP, Sanabria A, Ridge JA, Ng WT, de Bree R, Rinaldo A, et al. COVID-19 pandemic: effects and evidence-based recommendations for otolaryngology and head and neck surgery practice. Head Neck. 2020;42:1259-67.

7. Academy Supports CMS, Offers Specific Nasal Policy, ENT NET; 2020. Available from: https://www.entnet.org/content/academy-supports-cms-offers-specific-nasal-policy

8. AO CMF International Task Force Recommendations on Best Practices for Maxillofacial Procedures during COVID-19 Pandemic, AO CMF; 2020. Available from: https://www.aocmf3.aofoundation.org/\#0=news $\% 20$ date\%20facet,descending [Last accessed on 2020 Apr 12].

9. Recomendaciones de la SEORL-CCC Para la Práctica de la Especialidad Durante la Pandemia de COVID-19, SEORL; 2020. Available from: https://www.seorl.net/wp-content/uploads/2020/03/recomendaciones-dela-seorl-ccc-22-de-marzo-de-2020.pdf [Last accessed on $2020 \mathrm{Apr} 12$ ].

10. Brewster DJ, Chrimes N, Do T, Fraser K, Groombridge CJ, Higgs A et al. Consensus statement: safe Airway Society principles of airway management and tracheal intubation specific to the COVID-19 adult patient group. Med J Aust. 2020;212:472-81.

11. ENTUK Guidelines for Changes in ENT during COVID-19 Pandemic You are Here, ENT UK; 2020. Available from: https://www.entuk.org/entuk-guidelines-changes-ent-during-covid-19-pandemic-0 
12. Boccalatte LA, Larrañaga JJ, Raffo GM, Teijido CA, Fornari GG, Staneloni MI, et al. Brief guideline for the prevention of COVID-19 infection in head and neck and otolaryngology surgeons. Am J Otolaryngol. 2020;41:102484.

13. Bann DV, Patel VA, Saadi R, Gniady JP, Goyal N, McGinn JD, et al. Impact of Coronavirus (COVID-19) on otolaryngologic surgery: brief commentary. Head Neck. 2020;42:1227-34.

14. Tay JK, Khoo ML, Loh WS. Surgical considerations for tracheostomy during the COVID-19 pandemic: lessons learned from the severe acute respiratory syndrome outbreak. JAMA Otolaryngol Head Neck Surg. 2020;146:517-8.

15. Yang Y, Soh HY, Cai ZG, Peng X, Zhang Y, Guo CB. Experience of diagnosing and managing patients in oral maxillofacial surgery during the prevention and control period of the new coronavirus pneumonia. Chin J Dent Res. 2020;23:57-62.

16. Edwards SP, Kasten S, Nelson C, Elner V, McKean E. Maxillofacial trauma management During COVID-19: multidisciplinary recommendations. Facial Plast Surg Aesthet Med. 2020;22:157-9.

17. Kim HJ, Ko JS, Kim TY. Recommendations for anesthesia in patients suspected of COVID-19 Coronavirus infection. Korean J Anesthesiol. 2020;73:89-91.

18. ENT UK at the Royal College of Surgeons. Aerosol-Generating Procedures in ENT, ENT UK; 2020. Available from: https://www.entuk.org/sites/ default/files/aerosol-generating\%20procedures\%20in\%20ent_compressed.pdf [Last accessed on $2020 \mathrm{Apr} 11]$.

19. Gamage B, Moore D, Copes R, Yassi A, Bryce E, BC Interdisciplinary Respiratory Protection Study Group. Protecting health care workers from SARS and other respiratory pathogens: a review of the infection control literature. Am J Infect Control. 2005;33:114-21.

20. Wang J, Zhou M, Liu F. Reasons for healthcare workers becoming infected with novel Coronavirus disease 2019 (COVID-19) in China. J Hosp Infect. 2020;105(1):100-1.

21. Brat, G, Hersey S, Chhabra K, Gupta A, Scott J. Protecting surgical teams during the COVID-19 outbreak: a narrative review and clinical consideration. Ann Surg. 2020. In press. doi: 10.1097/ SLA.0000000000003926.

22. Parker N, Schiff B, Fritz M, Rapoport S, Schild S, Altman K. Tracheotomy Recommendations during the COVID-19 Pandemic, ENT NET; 2020. Available from: https://www.entnet.org/content/tracheotomy-recommendations-during-covid-19-pandemic [Last accessed on $2020 \mathrm{Apr} 12$ ].

23. Givi B, Schiff BA, Chinn SB, Clayburgh D, Iyer NG, Jalisi S, et al. Safety recommendations for evaluation and surgery of the head and neck during the COVID-19 pandemic. JAMA Otolaryngol Head Neck Surg. 2020;146:579-84

24. Ai T, Yang Z, Hou H, Zhan C, Chen C, Lv W, et al. Correlation of chest CT and RT-PCR testing for Coronavirus disease 2019 (COVID-19) in China: a report of 1014 cases. Radiology. 2020;296:E32-40.

25. Guidance for ENT Surgeons during the COVID-19 Pandemic, ASOHNS; 2020. Available from: http://www.asohns.org.au/about-us/news-and-announcements/latest-news?article=78 [Last accessed on 2020 Apr 11].

26. Wax RS, Christian MD. Practical recommendations for critical care and anesthesiology teams caring for novel Coronavirus (2019-nCoV) patients. Can J Anaesth. 2020;67:568-76.

27. Moore D, Gamage B, Bryce E, Copes R, Yassi A, BC Interdisciplinary Respiratory Protection Study Group. Protecting health care workers from SARS and other respiratory pathogens: organizational and individual factors that affect adherence to infection control guidelines. Am J Infect Control. 2005;33:88-96.

28. Lurie N, Carr BG. The role of telehealth in the medical response to disasters. JAMA Intern Med. 2018;178:745-6.

29. Nassar AH, Zern NK, McIntyre LK, Lynge D, Smith CA, Petersen RP, et al. Emergency restructuring of a general surgery residency program during the Coronavirus disease 2019 pandemic: The University of Washington experience. JAMA Surg. 2020;155:624-7.

30. Frerk C, Mitchell VS, McNarry AF, Mendonca C, Bhagrath R, Patel A, et al. Difficult airway society 2015 guidelines for management of unanticipated difficult intubation in adults. Br J Anaesth. 2015;115:827-48.

31. Apfelbaum JL, Hagberg CA, Caplan RA, Blitt CD, Connis RT, Nickinovich DG, et al. Practice guidelines for management of the difficult airway: an updated report by the American Society of Anesthesiologists task force on management of the difficult airway. Anesthesiology. 2013;118:251-70.

32. Rassekh CH, Jenks CM, Ochroch EA, Douglas JE, O'Malley BW, Weinstein GS. Management of the difficult airway in the COVID-19 pandemic: Illustrative complex head and neck cancer scenario. Head \& neck. 2020:42(6):1273-7.

33. Yang SS, Wang NN, Postonogova T, Yang GJ, McGillion M, Beique F, et al. Intravenous lidocaine to prevent postoperative airway complications in adults: a systematic review and meta-analysis. $\mathrm{Br} J$ Anaesth. 2020;124:314-23

34. Harrison L, Ramsden J, Winter S, Rocke J, Heward E. Guidance for Surgical Tracheostomy and Tracheostomy Tube Change during the COVID-19 Pandemic. United Kingdom: ENT; 2020. Available from: https:// www.entuk.org/tracheostomy-guidance-during-covid-19-pandemic [Last accessed on $2020 \mathrm{Apr} 11]$.

35. Chao T, Braslow B, Martin N, Chalian A, Atkins JH, Haas A, et al. Tracheotomy in ventilated patients with COVID-19. Ann Surg. 2020;272:e30-2.
36. Tunkel DE, Anne S, Payne SC, Ishman SL, Rosenfeld RM, Abramson PJ, et al. Clinical practice guideline: nosebleed (epistaxis). Otolaryngol Head Neck Surg. 2020;162 Suppl 1:S1-38.

37. The Cochrane Collaboration, editors. Tranexamic acid for epistaxis (nosebleeds). In: Cochrane Database of Systematic Reviews. Vol. 273. Chichester, UK: John Wiley \& Sons, Ltd.; 1996. p. 408.

38. Davies E, Hopkins C, Harries P, Walker A, Heward E. COVID-19 Epistaxis Management, United Kingdom: ENT; 2020. Available from: https:// www.entuk.org/sites/default/files/files/covid\%2019\%20epistaxis\%20management.pdf [Last accessed on 2020 Apr 12].

39. Iqbal IZ, Jones GH, Dawe N, Mamais C, Smith ME, Williams RJ, et al. Intranasal packs and haemostatic agents for the management of adult epistaxis: systematic review. J Laryngol Otol. 2017;131:1065-92.

40. Reyre A, Michel J, Santini L, Dessi P, Vidal V, Bartoli JM, et al. Epistaxis: the role of arterial embolization. Diagn Interv Imaging. 2015:96:757-73.

41. McClurg SW, Carrau R. Endoscopic management of posterior epistaxis: a review. Acta Otorhinolaryngol Ital. 2014;34:1-8.

42. Digoy GP. Diagnosis and management of upper aerodigestive tract foreign bodies. Otolaryngol Clin North Am. 2008;41:485-96, 487-8.

43. Springford LR, Jumanji K, Patel N. COVID-19 ADult Nasoendoscopy (FNE) and Possible Upper Aerodigestive Tract Fish Bone Investigation. United Kingdom: ENT; 2020. Available from: https://www.entuk.org/sites/default/ files/files/fish_bone_covid_19_protocol.pdf [Last accessed on 2020 Apr 11].

44. Davies E, Nick. R. Nasal Endoscopy and Laryngoscopy Examination of ENT Patients. ENT UK at The Royal College of Surgeons of England; 2020. Available from: https://www.entuk.org/sites/default/files/files/ nasal\%20endoscopy $\% 20$ and $\% 20$ laryngoscopy $\% 20$ examination $\% 20$ of $\% 20$ ent $\% 20$ patients_compressed.pdf

45. Vukkadala N, Qian J, Holsinger C, Patel Z, Rosenthal E. COVID-19 and the otolaryngologist: preliminary evidence-based review. Laryngoscope. 2020;130:2537-43

46. Vieira F, Allen SM, Stocks RM, Thompson JW. Deep neck infection. Otolaryngol Clin North Am. 2008;41:459-83, 87.

47. Dabirmoghaddam P, Mohseni A, Navvabi Z, Sharifi A, Bastaninezhad S, Safaei A. Is ultrasonography-guided drainage a safe and effective alternative to incision and drainage for deep neck space abscesses? J Laryngol Otol. 2017;131:259-63.

48. Biron VL, Kurien G, Dziegielewski P, Barber B, Seikaly H. Surgical vs ultrasound-guided drainage of deep neck space abscesses: a randomized controlled trial: surgical vs ultrasound drainage. J Otolaryngol Head Neck Surg. 2013;42:18.

49. Martin CA, Gabrillargues J, Louvrier C, Saroul N, Mom T, Gilain L. Contribution of CT scan and CT-guided aspiration in the management of retropharyngeal abscess in children based on a series of 18 cases. Eur Ann Otorhinolaryngol Head Neck Dis. 2014;131:277-82.

50. Al-Belasy FA. Ultrasound-guided drainage of submasseteric space abscesses. J Oral Maxillofac Surg. 2005;63:36-41.

51. Joo BY, Jang AL, Lee JH, Park HS, Kang MK, Hong JC. Application of ultrasound-guided pigtail catheter drainage for abscesses in the head and neck. Clin Otolaryngol. 2017;42:1087-91.

52. Battaglia A, Burchette R, Hussman J, Silver MA, Martin P, Bernstein P. Comparison of medical therapy alone to medical therapy with surgical treatment of peritonsillar abscess. Otolaryngol Head Neck Surg. 2018;158:280-6.

53. McNally G, Burgess A, Khwaja S, Ismail-Koch H, Davies E. ENT UK COVID-19 Adult Tonsillitis and Quinsy Guidelines. United Kingdom: ENT; 2020. Available from: https://www.entuk.org/sites/default/files/ent $\% 20$ uk\%20covid-19\%20tonsillitis\%20\%26\%20quinsy\%20guidelines $\% 20$ final. pdf [Last accessed on 2020 Apr 11].

54. Kawabata M, Umakoshi M, Makise T, Miyashita K, Harada M, Nagano H, et al. Clinical classification of peritonsillar abscess based on CT and indications for immediate abscess tonsillectomy. Auris Nasus Larynx. 2016;43:182-6.

55. Nogan S, Jandali D, Cipolla M, DeSilva B. The use of ultrasound imaging in evaluation of peritonsillar infections. Laryngoscope. 2015;125:2604-7.

56. Ashman A, Harris R. Outpatient management of patients with acute tonsillitis and peritonsillar abscess in ninety adult patients. Clin Otolarygol. 2017;42:720-3.

57. Sadeghirad B, Siemieniuk RA, Brignardello-Petersen R, et al. Corticosteroids for treatment of sore throat: systematic review and meta-analysis of randomised trials. BMJ. 2017;358:j3887.

58. Russell B, Moss C, George G, Santaolalla A, Cope A, Papa S, et al. Associations between immune-suppressive and stimulating drugs and novel COVID-19-a systematic review of current evidence. Ecancermedicalscience. 2020;14:1022.

59. Chang BA, Thamboo A, Burton MJ, Diamond C, Nunez DA. Needle aspiration versus incision and drainage for the treatment of peritonsillar abscess. Cochrane Database Syst Rev. 2016;12:CD006287.

60. Al Yaghchi C, Cruise A, Kapoor K, Singh A, Harcourt J. Out-patient management of patients with a peritonsillar abscess. Clin Otolaryngol. 2008;33:52-5.

61. Smith D, Montagne J, Raices M, Dietrich A, Bisso IC, Las Heras M, et al. Tracheostomy in the intensive care unit: guidelines during $\mathrm{CO}$ VID-19 worldwide pandemic. Am J Otolaryngol. 2020;41:102578.

62. Bleier BS, Ramanathan M Jr., Lane AP. COVID-19 vaccines may not prevent nasal SARS-CoV-2 infection and asymptomatic transmission. Otolaryngol Head Neck Surg. 2021;164:305-7. 